\title{
An African male with cough, haemoptysis, weight loss and hypercalcaemia: TB or not TB?
}

\author{
A.F. Al-Mobeireek*, M. Arafah", N. Siddiqui*
}

\section{Case history}

A 60-yr-old Sudanese male was referred to the University Hospital, Riyadh, Saudi Arabia, with the chief complaints of chronic cough productive of scanty sputum and occasional haemoptysis, anorexia and weight loss for 9 months. The patient was extensively investigated in other hospitals and was treated as a pulmonary tuberculosis (TB) patient on the basis of lymphocytic pleural fluid cytology and the

Table 1.-Relevant investigations

\begin{tabular}{lc}
\hline Test & Value \\
\hline $\mathrm{Hb}$ & $101 \mathrm{~g} \cdot \mathrm{L}^{-1}$ \\
ESR & $135 \mathrm{~mm} \cdot 1 \mathrm{st} \cdot \mathrm{h}^{-1}$ \\
Urea & $15 \mathrm{mmol} \cdot \mathrm{L}^{-1}$ \\
Creatinine & $167 \mathrm{mmol} \cdot \mathrm{L}^{-1}$ \\
Total protein & $126 \mathrm{~g} \cdot \mathrm{L}^{-1}$ \\
Albumin & $26 \mathrm{~g} \cdot \mathrm{L}^{-1}$ \\
Ig electrophoresis & Polyclonal IgG \\
Angiotensin converting & Normal \\
enzyme & Normal \\
Serum PTH & $8.80 \mathrm{kPa}$ \\
$P$ a,O & Negative \\
Urine for Bence-Jones & Negative \\
proteins & \\
Tuberculin test & $467 \times 10^{6} \cdot \mathrm{L}^{-1}$ \\
Pleural fluid & $(92 \%$ ymphocytes $)$ \\
WBC & $6000 \times 10^{6} \cdot \mathrm{L}^{-1}$ \\
& $4.9 \mathrm{mmol} \cdot \mathrm{L}^{-1}$ \\
RBC & $73 \mathrm{~g} \cdot \mathrm{L}^{-1}$ \\
Glucose & $370 \mathrm{IU} \cdot \mathrm{L}^{-1}$ \\
Protein & Negative for infection \\
LDH & and malignancy \\
Bone marrow aspirate & Normal \\
and trephine biopsy & Normal \\
Rectal biopsy & Negative \\
Bone scan & \\
Stains and cultures of sputa, & \\
bronchial wash and & \\
pleural fluid for bacteria, & \\
TB and fungi & \\
\hline
\end{tabular}

Hb: haemoglobin; ESR: erythrocyte sedimentation rate; Ig: immunoglobulin; PTH: parathyroid hormone; $\mathrm{Pa}, \mathrm{O}_{2}$ : oxygen tension in arterial blood; WC: white blood cell count; RBC: red blood cell count; LDH: lactate dehydrogenase; TB: tuberculosis. finding of granuloma on pleural biopsy. He continued to get worse, despite receiving four anti-TB drugs for the previous 4 months.

The patient's course was complicated by hypercalcaemia, which failed to respond to steroids and saline diuresis and required calcitonin. He also developed right-sided pneumothorax, which required prolonged thoracostomy drainage. He was a nonsmoker and worked as a painter.

On physical examination, the patient was cachectic, depressed and had finger clubbing. Furthermore, he had findings consistent with right pleural effusion.

A summary of investigations is shown in table 1. An initial chest radiograph is shown in figure 1. Selected images of computed chest tomography (CT) are shown in figure 2. In addition, the patient underwent a CTguided lung biopsy, which is shown in figure 3.

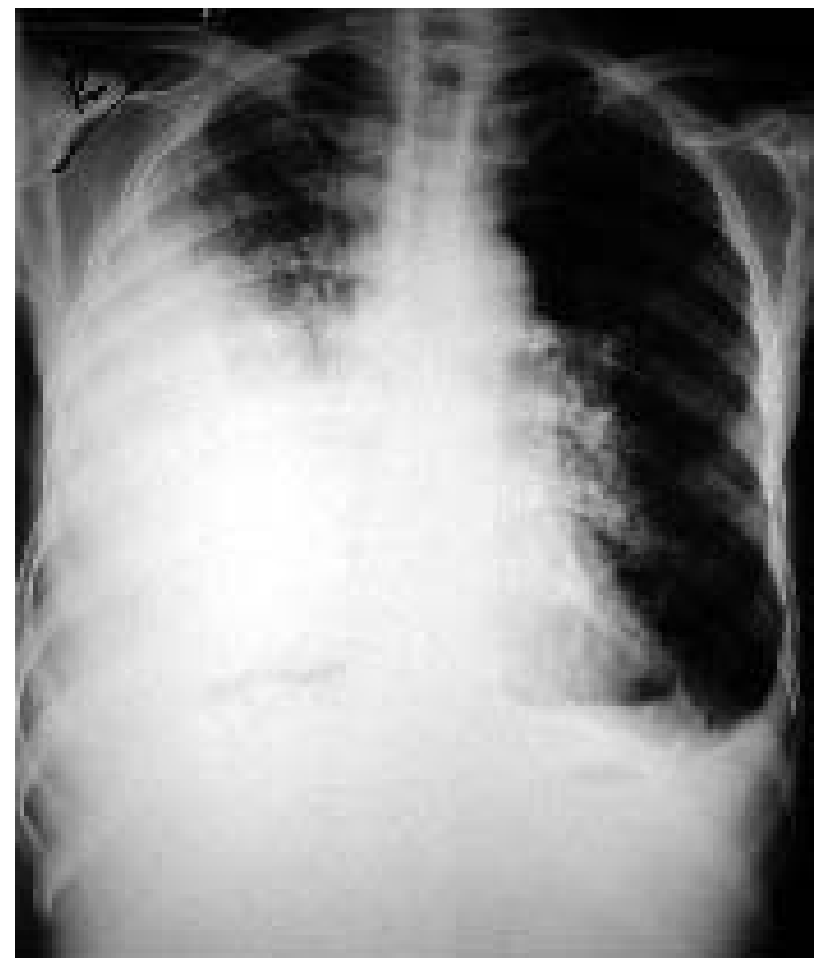

Fig. 1. - Chest radiograph.

\footnotetext{
*Dept of Medicine and ${ }^{\#}$ Dept of Pathology, College of Medicine, King Saud University, Riyadh, Saudi Arabia.

Correspondence: A.F. Al-Mobeireek, Dept of Medicine (38), College of Medicine, King Saud University, P.O. Box 2925, Riyadh 11461, Saudi Arabia. Fax: 966 14672686. E-mail: mobeireek@yahoo.com
} 

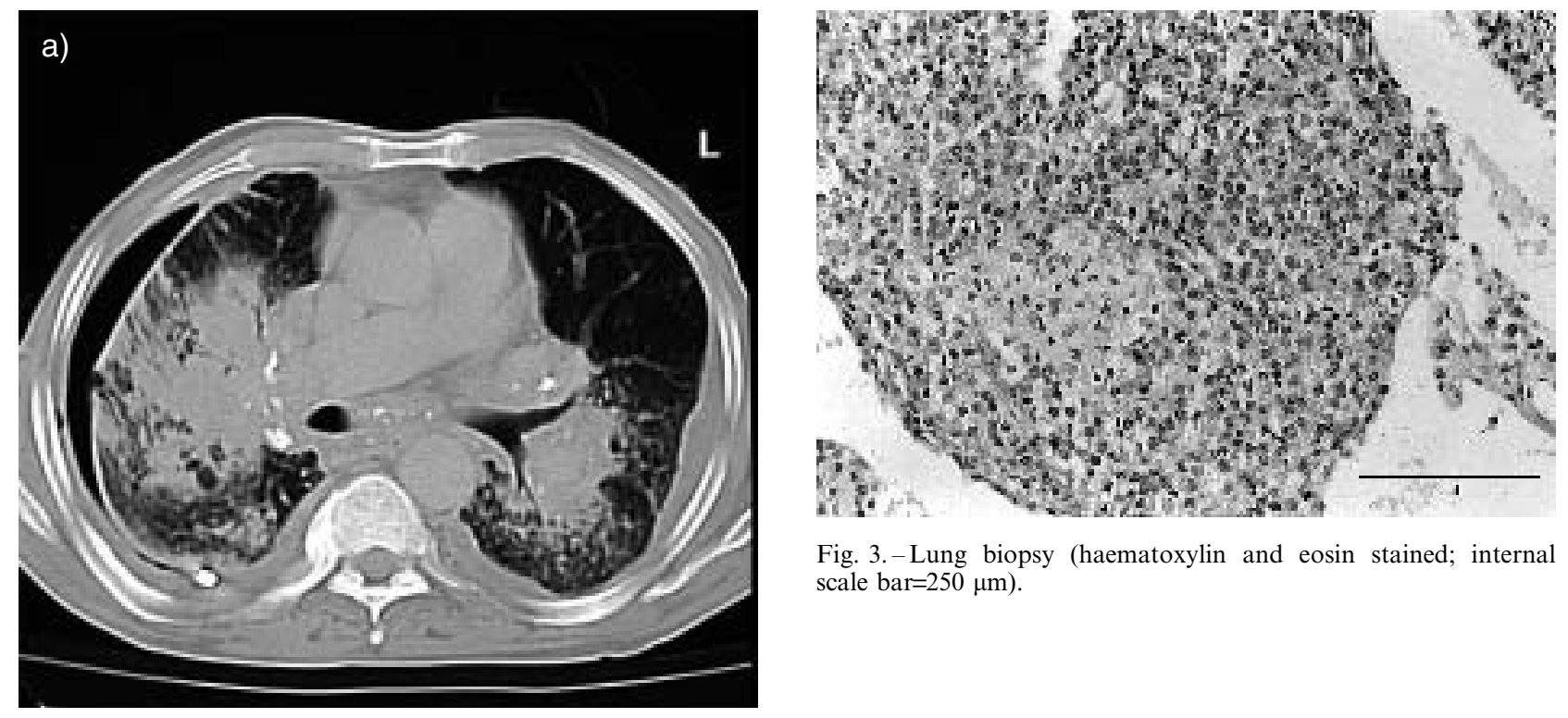

Fig. 3. - Lung biopsy (haematoxylin and eosin stained; internal scale bar $=250 \mu \mathrm{m}$ ).

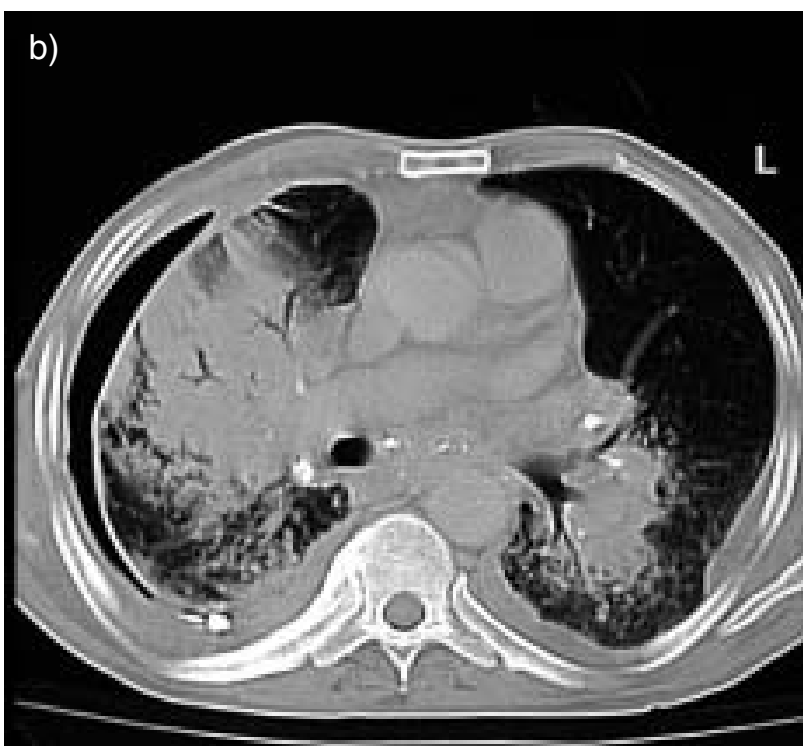

Fig. 2. - Selected cuts of computed tomographic images of the chest.

BEFORE TURNING THE PAGE, INTERPRET THE RADIOGRAPHS AND HISTOLOGICAL EXAMINATIONS AND SUGGEST A DIAGNOSIS. 


\section{Interpretation}

\section{Chest radiography}

The chest radiograph (fig. 1) shows a consolidation and a pleural effusion on the right as well as a small effusion on the left.

\section{Computed tomography}

The chest CTs (figs. 2a and b) show a consolidation with an air bronchogram, pleural effusion, pneumothorax and chest tube on the right side, and mediastinal lymphadenopathy with calcification. Site of the bronchopleural fistula can be seen in the periphery of the right lung in figure $2 \mathrm{a}$.

\section{Histological examination}

The histopathology of the lung biopsy (fig. 3) showed marked expansion of the interstitium, with dense infiltration by lymphocytes and ill-defined noncaseating epithelioid granulomas. The infiltrate was extending to the subendothelium of the small vascular walls, with no luminal involvement. Necrosis was absent. Cytologically, there was a mixture of small-to-medium sized lymphocytes with plasmacytoid appearance. There were a few large cells with vesicular nuclei and small prominent nucleoli. Many mature plasma cells with Russell bodies were also noted. Epithelioid cells constituted small and ill-defined granulomas. Most lymphocytes stained positively with B-cell marker (CD20) by immunohistochemical analysis. A few CD3 positive T-cells were also present. Immunohistochemical analyses for demonstration of light chain restriction were not conclusive. CD30 was negative. Review of the pleural biopsy (done previously in the referring hospital) showed similar cellular infiltrate with many ill-defined epithelioid granulomas and areas of dense fibrosis with calcifications.

\section{Diagnosis: "Primary pulmonary lymphoma (B-cell)"}

\section{Hospital course}

The patient received the first cycle of chemotherapy, which resulted in stabilisation of his clinical condition over the following month. The patient decided to travel back to his home country to complete his treatment there. There was no further follow-up.

\section{Discussion}

Although TB is endemic in the patient's geographical location and the clinical picture is compatible with TB (including hypercalcaemia [1]), a definite microbiological or histological proof was lacking. Granulomas without acid-fast bacilli or positive mycobacterial culture are not specific; a variety of infectious and noninfectious causes may be responsible (table 2) [2]. The patient's condition worsened despite antituberculous therapy. Other diagnoses that can cause chronic pulmonary infiltrates and hypercalcaemia that should be considered in this setting include sarcoidosis, malignancy (including lymphoma), multiple myeloma, and amyloidosis.

A diagnosis of sarcoidosis is supported by the presence of granulomas, hypercalcaemia, hypergammaglobulinaemia and a negative tuberculin test. All these features were present in the patient, except that he also had pleural effusion, which is unusual for sarcoidosis. He was also given steroids, without clinical improvement.

The presence of elevated erythrocyte sedimentation rate, anaemia, hyperproteinaemia, hypercalcaemia and renal insufficiency should also raise the possibility of multiple myeloma. This diagnosis is ruled out, however, by the negative bone marrow, the polyclonal nature of the gammopathy and the absence of BenceJones protein in the urine. Secondary amyloidosis, complicating his chronic pulmonary disease, may be considered because of the hypergammaglobulinaemia, hepatomegaly and renal insufficiency. Again, this is unlikely because of the relatively short period of his illness, the negative rectal biopsy and the radiological picture.

Carcinomatosis with hypercalcaemia is another consideration, but there was no evidence clinically or radiologically pointing to a primary tumour, and multiple organ biopsies were negative. In addition, many other conditions can cause pulmonary granuloma (not necessarily associated with hypercalcaemia), but there was no clinical or laboratory evidence to support any of these (table 2).

This leaves primary pulmonary lymphoma (PPL) for consideration, taking into account the histological picture and the lack of evidence of lymphoma elsewhere. PPL is not common, representing $\sim 3.6 \%$ of extranodal non-Hodgkin's lymphomas (NHL) [3]. Several histopathological subtypes of PPL have been

Table 2. - Differential diagnosis of pulmonary granulomas ${ }^{\#}$

Infections

TB

Fungal (e.g. aspergillosis, histoplasmosis, etc.)

Bacterial (e.g. brucellosis)

Parasitic (e.g. schistosomiasis, leshmaniasis)

Malignancies and lymphoproliferative disorders

PPL

MALT type NHL

LIP

Lymphatoid granulomatosis

Unknown aetiology

Sarcoidosis

Wegner's granulomatosis

Churg-Strauss syndrome

Bronchocentric granulomatosis

Environmental or occupational exposure

Hypersensitivity pneumonitis

Berylliosis

TB: tuberculosis; PPL: primary pulmonary lymphoma; MALT: mucosa-associated lymphoid tissue; NHL: nonHodgkin's lymphoma; LIP: lymphocytic interstitial pneumonitis. \#: for more details see reference [2]. 
described [4]. The four most distinct entities are: pulmonary lymphoma of B-cell phenotype and of lowgrade malignancy, B-cell lymphoma of high-grade malignancy, peripheral T-cell NHL, and lymphomatoid granulomatosis, whose clonal characterisation is sometimes difficult to confirm [5].

The most common types of low-grade B-cell PPL are well-differentiated lymphomas that originate from the mucosa-associated lymphoid tissue (low-grade MALT lymphoma). The typical site of MALT lymphoma in humans is the gastrointestinal tract. It has also been described in conjunctiva, salivary, thyroid and thymus glands. Most maltomas arise in the setting of an autoimmune disease or chronic antigenic stimulation. Involvement of the lung was described by ADDIs et al. [6] in 1988. Pulmonary maltomas are most often indolent and remain localised in the lung for long periods.

Epithelioid granulomas are known to be seen in pulmonary lymphoma. In one study [7], they were observed in $20 \%$ of 54 cases of low-grade malignant lymphoma. Their presence may be responsible for an erroneous diagnosis of TB in a small biopsy specimen, and their presence in conjunction with diffuse dense lymphoid infiltrate should be interpreted cautiously. Several ancillary methods (e.g. genetic analysis, multiparametric flow cytometry and gene amplification pattern) can be applied when working with small biopsies and cytological samples $[8,9]$.

In conclusion, lymphoproliferative diseases affecting the lung occur over a broad clinicopathological spectrum. Pulmonary lymphoma can mimic many diseases and should be considered in the differential diagnosis. Diagnosis can be difficult, as it requires adequate tissue sampling and a skilled pathologist. The presence of granulomas should not lead to the erroneous diagnosis of granulomatous diseases, particularly in the prescence of clonal lymphoplasmacytic infilterate, and if the clinicopathological setting is not typical.

Acknowledgements. The authors are grateful to A. Rikabi for reviewing the manuscript.

\section{References}

1. Al-Majid S, Sulimani R, El-Kassimi F, Pandya L, Huraib S, Al-Sharif N. Hypercalcemia in active pulmonary tuberculosis. Ann Saudi Med 1991; 11: 289-292.

2. Sharma OP, Flora G. Diagnosis of pulmonary granulomas in the tropics. Semin Respir Med 1991; 12: 124-135.

3. Freeman C, Beng TW, Cutter SJ. Occurrence and prognosis of extranodal lymphoma. Cancer 1972; 29: 252-260.

4. Habermann TG, Ryu JH, Inwards DJ, Kurtin PJ. Primary pulmonary lymphoma. Semin Oncol 1999; 126: 307-315.

5. Cadranel J, Antoine M, Bellocq A, Bernaudin JF, Milleron B, Mayaud C. Primary pulmonary lymphoma. Rev Mal Respir 1997; 14: 73-92.

6. Addis BJ, Hyjek E, Isaccson PG. Primary pulmonary lymphoma: a reappraisal of its histogenesis and its relationship to pseudolymphoma and lymphoid intestitial pneumonia. Histopathology 1988; 13: 1-17.

7. Fiche M, Capron F, Berger F, et al. Primary pulmonary non-Hodgkin's lymphomas. Histopathology 1995; 26: 529-537.

8. Zaer FS, Braylan RC, Zander DS, Iturraspe JA, Almasri NM. Multiparametric flow cytometry in the diagnosis and characterization of low-grade pulmonary mucosa-associated lymphoid tissue lymphomas. Mod Pathol 1998; 11: 525-532.

9. Nicholson AG, Wortherspoon AC, Diss TC, et al. Pulmonary B-cell non-Hodgkin's lymphoma. The value of immunohistochemistry and gene analysis in diagnosis. Histopathology 1995; 26: 395-403. 